\title{
Transplantation of human homograft aortic valve
}

\author{
MATTHIAS PANETH AND MARK F. O'BRIEN'
}

From the Brompton Hospital, London, S.W.3

We report the correction of aortic regurgitation by the insertion of a homograft aortic valve. The valve had been stored in buffered formaldehyde for six months, and this technique of preservation is the purpose of this communication.

Formaldehyde in acetate buffer for the preservation of valve tissue was suggested to us by Lord Brock (1962), and this report of its use is believed to be the first.

The successful implantation of homograft aortic valves in the subcoronary position was first reported by Ross $(1962,1963)$. In his series, homograft valves were removed under clean but nonsterile conditions within 12 hours of death, placed in a dilute chlorhexidine solution ('Hibitane'), and kept at approximately $4^{\circ} \mathrm{C}$. until they were finally trimmed at leisure. The valves were then sterilized by ethylene oxide and stored by freeze-drying. Barratt-Boyes (1963) has also had considerable success using freeze-dried valves. The homografts were taken under sterile technique from cadavers within 12 hours of death and put in Gross's nutrient medium (Gross, Bill, and Peirce, 1949). At weekly intervals the valves were removed from the medium, cultures were taken, and they were then freeze-dried and stored. Any contaminated valves were discarded. In his series of 32 patients, there were only two deaths, and no case of graft failure was reported. The longest follow-up has been almost one and a half years.

It is interesting to note that the classical homograft rejection does not occur with cardiac valves preserved in this way. Murray $(1956,1960)$ reported his experiences with valves in the descending thoracic aorta, and Kerwin, Lenkei, and Wilson (1962) reviewed these patients up to six and a half years post-operatively. Pressure measurements across the homograft valve at that time showed good diastolic gradients.

\section{PRESERVATION AND LATE VALVE FUNCTION}

There is now good evidence to show that homograft aortic valves can be used successfully

1Present address : St. Vincent's Hospital, Melbourne, Australia in the treatment of aortic valve disease. But there is no knowledge of their long-term fate nor of the possibility of delayed degeneration. The immediate function of the valve does not seem to depend upon the method of preservation. If degenerative changes, such as fibrosis and myxomatous and subsequent calcific infiltrations, occur, then these could be directly related to the techniques of preservation. At the present time, aortic valves which have been either freeze-dried or preserved in nutrient medium or acid formaldehyde have been inserted by various workers, and only long-term follow-up studies will indicate which method is the least likely to produce these degenerative changes.

\section{BUFFERED ACID FORMALDEHYDE PRESERVATION}

Levin and Larkin (1908, 1909), Ward (1908), and Guthrie (1919) used formaldehyde as a preservative of aortic segments, and one of the latter's experimental animals had a formaldehydepreserved artery in place for 11 years.

Interest in formaldehyde preservation returned in 1949 with reports by Gross, Bill, and Peirce (1949). They believed that formaldehyde buffered to an acid $p \mathrm{H}$ was more advantageous than neutral solutions because the vessel wall was stronger, its elastic fibre network better preserved, and the whole structure less likely to rupture or calcify. Exhaustive experiments by Moeys, Mreyen, and Den Hartog (1954), reviewed by Nuboer (1954), suggested that aortic grafts preserved in formaldehyde were less likely to degenerate provided the solution was buffered to a constant $p H$ of $5 \cdot 6$. Grafts preserved in neutral solution were soft, and after implantation in dogs disruption occurred in most instances.

These Dutch workers showed that the elastic network of the transplanted, formaldehyde-preserved artery was extremely resistant, and signs of degeneration were found only after a considerable period of time. This delay in fibre decomposition of the donor tissue elements is thought to be due to the effect of formaldehyde on proteins which 
causes polycondensation of the protein molecules ; because of their size these large molecules are less susceptible to chemical change.

We believe that the important constituent of the valve homograft is the elastic tissue, which serves as a framework, while dead donor graft endothelium and matrix are slowly and gradually replaced by the host. This pattern of substitution has been seen in experimental studies by several workers (O'Brien and Gerbode, 1966 ; Lower and Shumway, 1963 ; McKenzie, 1963 ; Berghuis, Rastelli, Van Vliet, Swan, and Ellis, 1963).

\section{TECHNIQUE OF PRESERVATION}

Aortic valves were removed by a clean, but not sterile, technique from cadavers several hours after death and placed in a solution of $4 \%$ formaldehyde buffered to a $p \mathrm{H}$ of $5 \cdot 6$.

The solution is prepared by diluting one part of $40 \%$ formaldehyde in nine parts of acetic acidsodium acetate buffer. The acetic acid-sodium acetate buffer is obtained by mixing $9.5 \mathrm{ml}$. of $0.2 \mathrm{M}$ acetic acid with $90.5 \mathrm{ml}$. of $0.2 \mathrm{M}$ sodium acetate.

With the valve in this solution the $p \mathrm{H}$ is checked at the end of one week. The solution is changed if the $p \mathrm{H}$ drifts to higher levels. Usually the $p \mathrm{H}$ stabilizes quickly, and one or two changes only are required. At a convenient time the valve is trimmed and measured across its basal diameter. The solution is self-sterilizing, and therefore the trimmed graft will be sterile after being in the solution for two to four hours, depending on the bulk of the valve.

On the morning of operation the valve is removed from the formaldehyde solution, washed in sterile saline several times, and soaked in a heparin and penicillin mixture for as long as convenient before insertion.

A homograft aortic valve preserved in this way was sewn into position on 15 November 1962. The patient made a good recovery and was last seen on 4 December 1964. His blood pressure before operation was $150 / 0 \mathrm{~mm}$. $\mathrm{Hg}$, and at the last follow-up was $140 / 60 \mathrm{~mm}$. $\mathrm{Hg}$, with mild regurgitation only. This regurgitation occurred on the tenth post-operative day and has not increased since.

\section{DISCUSSION}

Formaldehyde preservation has the advantages of being simple and self-sterilizing. The valve homograft is not a living structure. Formaldehyde affords adequate preservation of the elastic fibres of the valve matrix, and we presume that sufficient support is maintained while host endothelium is deposited on the surface and fibroblasts grow in from the base.

There have been no known or reported cases of thrombosis on human homograft valves irrespective of the method of preservation. Exparimentally, unless there is infection, clots do not occur. and therefore anticoagulants have not been used in these cases.

Experimental work by McKenzie (1963) with various valve preservation techniques suggests that non-viable homografts are replaced by host tissue rapidly with minimal cusp thickening. Further study of a large series of cases over subsequent years will determine which method of preservation is the best.

\section{SUMMARY}

The use of $4 \%$ formaldehyde, buffered to a constant $p \mathrm{H}$ of $5 \cdot 6$, as a preservative for human homograft cardiac valves has been presented. The experiences of others with aortic segment preservation is discussed, and the possible advantages of formaldehyde are outlined. The method is simple. rapid, self-sterilizing, and efficient, and the problems of developing a donor valve bank are minimal.

We believe that protein denaturation retards degeneration of the donor tissue and prevents rejection by the host. Elastic networks are preserved, and structure is maintained while host replacement of the valve homograft is taking place.

A successful homograft aortic valve transplantation in a 32-year-old man is described. The object of this communication has been to report a 24month follow-up of this patient whose homograft valve had previously been preserved for more than six months in formaldehyde.

\section{REFERENCES}

Barratt-Boyes, B. (1963). Personal communication. Data to be published.

Berghuis, J., Rastelli, G. C., Van Vliet, P. D., Swan, H. J. C., and Ellis, F. H. (1963). Homotransplantation of the canine mitral valve. Circulation, 28, 689.

Brock, R. C. (1962). Personal communication.

Gross, R. E., Bill, A. H., and Peirce, E. C. (1949). Methods for preservation and transplantation of arterial grafts. Surg. Ginec. Obstet., 88, 689 .

Guthrie, C. C. (1919). End-results of arterial restitution with devitalized tissue. J. Amer. med. Ass., 73, 186.

Kerwin, A. J., Lenkei, S. C., and Wilson, D. R. (1962). Aortic-valve homograft in the treatment of aortic insufficiency. New Engl. J. Med., $266,852$.

Levin, I., and Larkin, J. H. (1908). Transplantation of devitalized arterial segments. Proc. Soc. exp. Biol. (N.Y.), 5, 109. - (1909). Transplantation of devitalized arterial segments: morphological changes in the implanted segments. $J$. med. Res., 21, 319. 
Lower, R. R., and Shumway, N. E. (1963). Replacement of the dog mitral valve with a homograft. Surg. Forum, 14, 247.

McKenzie, M. (1963). Personal communication.

Moeys, E. J., Mreyen, F. W., and Den Hartog, B. J. C. (1954). Homotransplantation of formaldehyde-preserved arteries in dogs. Arch. Chir. Neerl., 6, 333.

Murray, G. (1956). Homologous aortic-valve-segment transplants as surgical treatment for aortic and mitral insufficiency. Angiology, 7,466 .

(1960). Aortic valve transplants. Ibid., 11, 99.
Nuboer, J. F. (1954). Treatment of certain coarctations with homologous grafts, fixed in 4\% formalin. Arch. Chir. Neerl., 6, 123.

O'Brien, M. F., and Gerbode, F. (1966). Homotransplantation of the canine mitral valve. Lancet. In the press.

Ross, D. N. (1962). Homograft replacement of the aortia valve. Ibid., $2,487$.

(1963). Surgical reconstruction of the aortic valve. Ibid., 1, 571.

Ward, W. (1908). Histological changes in transplanted blood vessels. Proc. Soc. exp. Biol. (N.Y.), 5, 112. 